\title{
The dynamic behavior of feed efficiency in primiparous dairy cattle
}

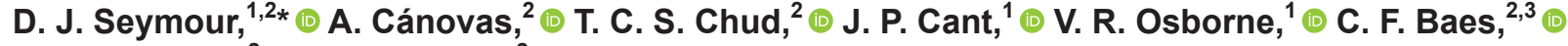 \\ F. S. Schenkel, ${ }^{2}{ }^{\circ}$ and F. Miglior ${ }^{2}(1)$ \\ ${ }^{1}$ Centre for Nutrition Modelling, Department of Animal Biosciences, University of Guelph, Ontario N1G 2W1, Canada \\ ${ }^{2}$ Centre for Genetic Improvement of Livestock, Department of Animal Biosciences, University of Guelph, Ontario N1G 2W1, Canada \\ ${ }^{3}$ Institute of Genetics, Vetsuisse Faculty, University of Bern, Switzerland 3001
}

\begin{abstract}
A variety of measures are currently used to evaluate feed efficiency in livestock, with some of the most popular being the linear regression of nutrient intake on the various energy sinks of the cohort being evaluated. The adoption of novel on-farm technologies has greatly increased the breadth and depth of data being collected on a daily basis, which creates the opportunity for the implementation of more advanced feed efficiency models. The objectives of the current study were to leverage data collected using high-throughput biometric technologies to evaluate changes of early-lactation feed efficiency on a daily basis and to develop a novel measure of feed efficiency based on the NRC net energy model. Daily records of nutrient intake, fat- and protein-corrected milk yield, body weight, and body condition score were used to model 7 different indices of feed efficiency (gross feed efficiency, return over feed costs, residual feed intake, residual net energy intake, and net energy efficiencies of lactation, maintenance, and body reserve flux) in primiparous Holstein heifers $(\mathrm{n}=40)$ from 0 to $150 \mathrm{~d}$ in milk. We observed that feed efficiency was dynamic and fluctuated over the course of the experimental period regardless of the efficiency measure used, but most measures followed similar trends in changes of efficiency on a day-to-day basis. Of the measures evaluated, return over feed costs would be most suited for management purposes due to practicality and simplicity, whereas other measures, such as the efficiency of net energy flux to and from body reserves, present potential targets for inclusion in breeding goals. Net energy efficiency of lactation was estimated to have higher repeatability compared with residual feed or energy intake, which may reduce the time required to estimate whole-lactation efficiency. Because decreased net energy balance was strongly correlated with increased efficiency for all indices evalu-
\end{abstract}

Received August 6, 2019.

Accepted October 17, 2019

*Corresponding author: seymourd@uoguelph.ca ated, future work investigating the associations of feed efficiency with the magnitude and duration of negative energy balance is warranted.

Key words: feed efficiency, net energy

\section{INTRODUCTION}

Feed is typically the single largest expense in dairy production, accounting for approximately $46 \%$ of total costs of production (USDA-ERS, 2019). This has spurred research into breeding animals that use feed more efficiently, thereby reducing feed costs per unit of product, such as milk (VandeHaar et al., 2016; Miglior et al., 2017; Brito et al., 2019). Because there is no single universal definition of feed efficiency, multiple measures can be used to describe how efficiently animals convert feed into product. Residual feed intake (RFI) is one of the most popular measures of feed efficiency currently used in research settings (Connor et al., 2019; Flay et al., 2019; Shonka-Martin et al., 2019). Originally developed by Koch et al. (1963) in growing beef steers and more recently applied in other species, it represents the linear regression of DMI on factors representing the various energy sinks (e.g., maintenance, growth, lactation) of a group of animals over a defined period of time, with the measure of efficiency being the residual error of the DMI prediction (hence "residual feed intake"). Similar regression-based methods have been applied to dairy animals that regress energy intake in place of DMI (Fischer et al., 2018a).

Although regression-based methods are convenient and make estimation of feed efficiency relatively simple, the growing adoption of on-farm high-throughput technologies (e.g., in-line body weight scales and body condition score cameras) have greatly increased the quantity and variety of data being generated daily. This offers the opportunity to integrate these data into more sophisticated and functionally based models, such as the NRC net energy model (NRC, 2001), which could allow for a more robust estimate of feed efficiency. As such, the objective of this study was to integrate data collected using high-throughput biometrics technologies 
into novel, net energy-based measures of feed efficiency and compare daily estimates to those of traditional feed efficiency measures.

\section{MATERIALS AND METHODS}

All procedures involving animals were approved by the University of Guelph Animal Care Committee (Animal Utilization Protocol \#3503). Data used in this study were collected as part of the ongoing Efficient Dairy Genome Project (http://genomedairy.ualberta .ca) between August 2016 and December 2018 from 191 primiparous Holstein heifers aged $2.08 \pm 0.20$ (mean \pm $\mathrm{SD)}$ years at calving.

\section{Housing and Management}

Animals were housed at the Livestock Research and Innovation Centre-Dairy (Centre Wellington, ON, Canada). Over the course of the experimental period, animals were housed in 2 different areas of the barn: the main freestall area of the barn and the tiestall area where animals were housed when undergoing evaluation of methane emissions for $7 \mathrm{~d}$ at $128 \pm 6$ DIM. In the main barn, cows either were milked twice daily at $0500 \mathrm{~h}$ and $1700 \mathrm{~h}$ in a rotary parlor (DeLaval, Tumba, Sweden) or were housed in a pen with access to a voluntary milking system (VMS; DeLaval) which animals visited $3 \pm 1$ times per day on average. Animals housed in the tiestall barn were milked in place at $0530 \mathrm{~h}$ and $1730 \mathrm{~h}$. Feed in the main barn was provided ad libitium via Insentec Roughage Intake Control feed bunks (Hokofarm Group B.V., Marknesse, the Netherlands) that were refilled 1 to 2 times daily, depending on use. If animals were housed with access to the VMS, they were offered a partial mixed ration that differed from the TMR offered to the rest of the milking herd (Table 1), to account for the pellet offered in the VMS. During the methane testing period in the tiestall barn, feed was delivered daily at $1100 \mathrm{~h}$ with approximately $25 \%$ of their daily ad libitium allotment offered after each methane testing session at $1200 \mathrm{~h}$ and $1600 \mathrm{~h}$, with the remaining $50 \%$ offered after the session at $2000 \mathrm{~h}$. Animals had ad libitum access to water in all areas.

\section{Data Collection}

Milk Yield and Composition. Milk weights at each session were either recorded automatically in the rotary milking parlor and VMS or manually in the tiestalls. Milk samples were collected weekly at alternating morning or evening milkings for composition analysis, including protein and fat, by CanWest DHI (Guelph,
ON, Canada). Milk composition samples were considered representative for all milkings for that animal in that calendar week.

DMI. When cows were housed in the main barn, feed intake was recorded automatically by the Insentec feed bunks. The feed bunks were cleaned and refilled daily and recalibrated every 4 mo. When housed with access to the VMS, the amount of pellet offered at each milking session was recorded automatically in addition to the feed intakes recorded by the Insentec feed bunks.

Table 1. Average TMR and partial mixed ration ingredients and chemical composition of feeds offered over the experimental period; values are presented as percentage of DM unless stated otherwise

\begin{tabular}{lccr}
\hline Item & TMR & $\begin{array}{c}\text { VMS }^{2} \text { partial } \\
\text { mixed ration }\end{array}$ & $\begin{array}{c}\text { VMS } \\
\text { pellet }^{3}\end{array}$ \\
\hline Ingredient & & & \\
Corn silage & 30.24 & 37.44 & \\
Haylage & 28.77 & 35.91 & \\
High-moisture corn & 26.40 & 11.90 & \\
Supplement & $12.63^{4}$ & $12.70^{5}$ & \\
Chopped straw & 1.95 & 2.05 & \\
Composition & & & \\
DM (\%) & 45.12 & 43.96 & 92.65 \\
CP & 14.74 & 14.90 & 20.51 \\
Soluble CP (\% CP) & 56.75 & 56.12 & 26.04 \\
UIP ${ }^{6}$ (\% CP) & 21.62 & 21.94 & 27.86 \\
ADICP & 1.11 & 1.11 & 0.71 \\
NDICP & 1.78 & 2.00 & 1.82 \\
ADF & 22.24 & 24.73 & 13.44 \\
NDF & 32.50 & 36.00 & 24.57 \\
Lignin & 2.91 & 3.35 & 1.63 \\
TDN & 71.57 & 69.60 & 73.72 \\
Crude fat & 3.11 & 3.22 & 2.22 \\
NE $_{\mathrm{L}}{ }^{7}$ (Mcal/kg of DM) & 1.64 & 1.59 & 1.69 \\
Ca & 0.85 & 0.93 & 0.66 \\
P & 0.42 & 0.42 & 0.56 \\
\hline${ }^{1}$ UIP &
\end{tabular}

${ }^{1} \mathrm{UIP}=$ undegradable intake protein $; \mathrm{ADICP}=$ acid detergent insoluble $\mathrm{CP}$ : $\mathrm{NDICP}=$ neutral detergent insoluble $\mathrm{CP}$.

${ }^{2} \mathrm{VMS}=$ voluntary milking system.

${ }^{3}$ Dairy robot pellet (Floradale Feed Mill Ltd., Floradale, ON).

${ }^{4}$ Manufactured by Floradale Feed Mill Ltd. and contained on average (\% of DM) Soy Plus (31.6; Landus Cooperative, Ames, IA), $47 \%$ CP soybean meal (26.0), canola (11.4), limestone calcium carbonate (4.8), sodium chloride (4.7), wheat shorts (4.5), sodium sesquicarbonate (4.4), monocalcium phosphate (3.0), magnesium oxide (2.5), Original XP yeast (2.3; Diamond V, Cedar Rapids, IA), vitamin/mineral premix (1.2; Floradale Feed Mill Ltd.), tallow (0.94), potassium carbonate (0.85), MetaSmart (0.80; Adisseo, Alpharetta, GA), sulfur (0.49), urea (0.45), Rumensin (0.06; Elanco, Greenfield, IN), and Selplex 2000 (0.02; Alltech, Nicholasville, KY).

${ }^{5}$ Manufactured by Floradale Feed Mill Ltd. and contained on average (\% of DM) Soy Plus (49.2; Landus Cooperative), $47 \%$ CP soybean meal (15.7), canola (11.4), limestone calcium carbonate (4.8), sodium chloride (4.7), wheat shorts (4.5), sodium sesquicarbonate (4.4), monocalcium phosphate (3.0), magnesium oxide (2.5), Original XP yeast (2.3; Diamond V), vitamin/mineral premix (1.2), tallow (0.94), potassium carbonate (0.85), MetaSmart (0.80; Adisseo), sulfur (0.49), urea (0.45), Rumensin (0.06; Elanco), and Selplex 2000 (0.02; Alltech). ${ }^{6}$ Determined by wet chemistry.

${ }^{7} \mathrm{NE}_{\mathrm{L}}=0.0245 \times \mathrm{TDN}(\%)-0.12(\mathrm{NRC} 2001)$. 
In the tiestalls, the weight of orts was subtracted from the weight of feed offered each day to determine feed intake. Representative samples of all rations offered were collected weekly and analyzed for DM content as described by Seymour et al. (2019). Additional samples were collected weekly and pooled by month for proximate analysis, which was performed by A\&L Canada Laboratories (London, ON). Weekly DM samples were considered representative for all rations offered in that calendar week, and monthly proximate analysis samples were considered representative of the nutrient content of rations offered in that month. Average formulations and nutrient contents of all feeds offered over the experimental period are provided in Table 1 .

$B W$ and $B C S$. Body weights were recorded manually biweekly, using a conventional scale from August 2016 to November 2017. Starting in March 2017, BW were recorded automatically upon exiting the rotary milking parlor with an in-line scale (DeLaval). Body weight records collected between March and November 2017 were used to confirm that measurements taken on both devices were well correlated $(r=0.76)$. Animals that were housed with the VMS had BW recorded 3 times per week when using the footbaths. Body condition score cameras (DeLaval; Mullins et al., 2019) were installed on both the rotary parlor and the VMS in February 2017, which allowed for the automatic estimation of BCS on both systems after each milking session.

\section{Data Analysis}

Data Preparation. All analyses were performed using SAS v. 9.4 (SAS Institute Inc., Cary, NC). All data were merged to form individual daily records for each animal from 0 to 150 DIM of the first lactation. Raw data were screened for outliers using the UNIVARIATE procedure. If an observation was more than 2.5 standard deviations (SD) above or below the mean, it was considered an outlier and treated as a missing observation for all subsequent analyses. Records for milk yield and feed intake were summed within days to generate daily records. Weekly feed DM records and monthly proximate analyses were merged with daily feed intake records by calendar week and month, respectively. These records were then used to generate daily estimates of DM and nutrient intakes. Similarly, weekly milk composition records were merged with daily milk records by calendar week and used to estimate daily milk component yields. Daily fat- and protein-corrected milk (FPCM) yields were calculated according to Tyrrell and Reid (1965). Daily records were then smoothed using the TRANSREG procedure with a smoothing parameter of 50 (Spurlock et al., 2012), similar to the methodology proposed by Thorup et al. (2018). Following smooth- ing, the daily change in BW and BCS were calculated as the numerical difference in smoothed records from the preceding day. We observed that missing records at either the start or the end of the observational period resulted in physiologically impossible smoothed values. As such, animals that had fewer than 5 daily records for milk yield, DMI, BW, or BCS in the first or last $14 \mathrm{~d}$ of the experimental period were excluded. This resulted in a data set based on records from 40 animals. No adjustments were made to $\mathrm{NE}_{\mathrm{L}}$ intake to account for decreased digestibility at increasing levels of feed intake.

Estimation of Traditional Feed Efficiency Measures. All measures of feed efficiency were calculated on a daily basis using smoothed records. Gross feed efficiency (GFE) was calculated as the ratio of FPCM to DMI. Return over feed costs (ROFC) was calculated as the difference between milk income and feed costs. The price per kilogram of DM was set to Can $\$ 0.25$ (Can $\$ 1.00$ equals approximately US\$0.77) and was based on a previous formulation of the ration fed. The prices of milk fat and protein were Can $\$ 10.65$ and Can $\$ 7.27$ per $\mathrm{kg}$, respectively, and were based on the average within-quota producer prices for the previous 12 mo, as reported by Dairy Farmers of Ontario (Mississauga, ON, Canada).

RFI was predicted using the MIXED procedure of SAS according to the following model:

$$
\begin{aligned}
D M I_{i j}= & \mu+D I M_{j}+b_{1} M B W_{i}+b_{2} \Delta B W_{i}+b_{3} B C S_{i} \\
& +b_{4} \Delta B C S_{i}+b_{5} F P C M_{i}+R F I_{i j},
\end{aligned}
$$

where $D M I_{i j}$ is the observed DMI for cow $i$ on the $j$ th DIM (0 to 150), $\mu$ is the overall mean, $D I M_{j}$ is the fixed effect of the $j$ th DIM, $b_{1}$ is the regression coefficient of DMI on metabolic body weight (MBW; $\mathrm{BW}^{0.75}$ ) measured on cow $i$ on the $j$ th DIM, $b_{2}$ is the regression coefficient of DMI on the change in BW $(\Delta \boldsymbol{B} \boldsymbol{W})$ measured on cow $i$ on the $j$ th DIM, $b_{3}$ is the regression coefficient of DMI on BCS measured on cow $i$ on the $j$ th DIM, $b_{4}$ is the regression coefficient of DMI on the change in BCS $(\boldsymbol{\Delta} \boldsymbol{B} \boldsymbol{C S})$ measured on cow $i$ on the $j$ th DIM, $b_{5}$ is the regression coefficient of DMI on FPCM yield of cow $i$ on the $j$ th DIM, and $R F I_{i j}$ is the residual error term (RFI) with $\sim \operatorname{IND}\left(0, \sigma_{e}^{2}\right)$, where $\sigma_{e}^{2}$ is the variance of the residual error, based on the model used by Byskov et al. (2017). Residual net energy intake (REI; Fischer et al., 2018a) was predicted using a similar model, substituting dietary $\mathrm{NE}_{\mathrm{L}}$ intake for $\mathrm{DMI}$ and milk $\mathrm{NE}_{\mathrm{L}}$ content for FPCM.

Net Energy Modeling. Smoothed records were used to model daily net energy flows based on the NRC (2001) net energy model. All equations used are 
presented in Supplemental Table S1 (https://doi.org/ 10.3168/jds.2019-17414), along with the corresponding NRC equation number where applicable, and a visual representation of the model is provided in Figure 1. Net energy partitioned toward maintenance (NEMaint) was calculated assuming a conceptus weight of zero and no additional energy expenditure for activity above that which is included in the base estimate. When estimating net energy partitioned toward lactation (NELact), milk energy content per kilogram was calculated assuming a constant lactose content of $4.85 \%$. Available net energy (NEAvail) is a novel energy pool not included in the conventional NRC model. It represents the total amount of energy available for partitioning by the animal and accounts for the influx of energy from the diet as well as the flow of energy to or from body reserves, respectively. Energy pools (i.e., NEAvail and reserve energy) were estimated in units of Mcal of $\mathrm{NE}_{\mathrm{L}}$, whereas energy fluxes (e.g., NEMaint, NELact) were estimated in units of Mcal of $\mathrm{NE}_{\mathrm{L}}$ per day.

When comparing the reserve energy equations to NRC (2001) equations 2-24 and 2-25 (Supplemental Table S1; https://doi.org/10.3168/jds.2019-17414), the signs of the partial efficiency of energy use are reversed. This is to adequately characterize the effects on the NEAvail pool; a negative $\Delta R E$ represents a contribution to NEAvail from body reserves, whereas a positive $\triangle R E$ represents a flow of energy out of NEAvail to body reserves. It was also assumed that when calculating $\Delta R E$, any energy influx or efflux from body reserves was applied to energy calculations on that DIM, as op-

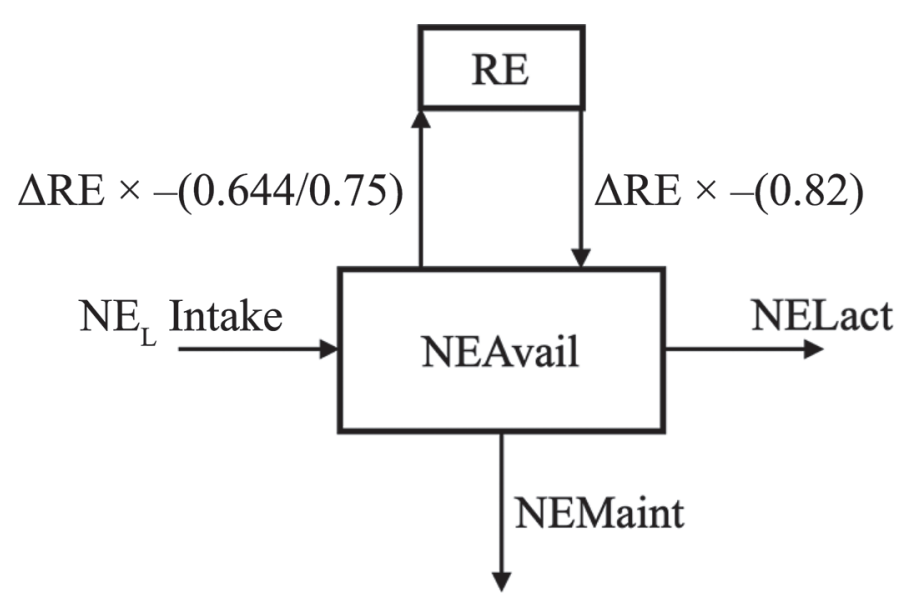

Figure 1. Visual representation of the net energy model as proposed by NRC (2001). Boxes represent energy pools (Mcal of $\mathrm{NE}_{\mathrm{L}}$ ), arrows represent energy fluxes (Mcal of $\mathrm{NE}_{\mathrm{L}}$ per day). $\mathrm{RE}=$ reserve energy; NEAvail = available net energy; NELact = net energy partitioned toward lactation; NEMaint = net energy partitioned toward maintenance. posed to using a lag function to apply these changes to the previous DIM. Furthermore, energy expenditures related to animal growth were accounted for in the accumulation of body reserves.

The novel measures of feed efficiency calculated herein are the $\mathrm{NE}_{\mathrm{L}}$ efficiency of lactation $\left(\mathbf{N E E}_{\mathbf{L}}\right)$, maintenance $\left(\mathbf{N E E}_{\mathbf{M}}\right)$, and reserve energy flux $\left(\mathbf{N E E}_{\mathbf{F}}\right)$. They represent the proportion of NEAvail that is estimated to move through each respective flux and provide measures that are more representative of the underlying biological processes relating to energy and feed efficiency.

Comparison of Feed Efficiency Measures. The CORR procedure of SAS was used to calculate correlations between daily measures of feed efficiency, as well as each measure of feed efficiency with DMI, FPCM yield, BW, BCS, and net energy balance. To assess the behavior of each measure of feed efficiency over time within animals, daily measures were rescaled to a mean of 0 and SD of 1 across animals within DIM using the STANDARD procedure of SAS. Standardized measures were then plotted over time within animal and visually assessed, and correlations between daily values were estimated using the CORR procedure of SAS. The variance and $\mathrm{CV}$ of each measure were evaluated both across and within animals using the UNIVARIATE procedure. Due to the nature of RFI and REI being normally distributed around a mean of zero, values for each measure were recentered around the intercept of its respective model $(8.82 \mathrm{~kg}$ of DM/d for RFI; 13.92 Mcal of $\mathrm{NE}_{\mathrm{L}} / \mathrm{d}$ for REI) to allow for the calculation of CV between animals. An ANOVA for each measure of feed efficiency was performed using the GLM procedure with animal and DIM as class effects. The repeatability of each measure was calculated as

$$
R=\frac{M S_{A}-M S_{E}}{M S_{A}+(n-1) \times M S_{E}}
$$

where $R$ is the repeatability, $M S_{A}$ is the mean square of the effect of animal, $M S_{E}$ is the mean square error, and $n$ is the sample size per animal (adjusted as necessary in cases of unequal records per animal; Nakagawa and Schielzeth, 2010).

\section{RESULTS AND DISCUSSION}

\section{Smoothed Input Records}

The daily averages of smoothed DMI, FPCM, BW, and BCS, along with the associated 95\% confidence intervals, are presented in Figure 2. The DMI steadily increased until approximately 75 DIM, when daily 
intakes plateaued at roughly $20 \mathrm{~kg} / \mathrm{d}$. Daily FPCM yield reached an average plateau of $32 \mathrm{~kg} / \mathrm{d}$ at 40 DIM and began to decline at 135 DIM. The BW sharply declined until 35 DIM and then steadily increased for the remainder of the experimental period, as would be expected with the normal growth of first-parity cows. The BCS declined gradually from 3.6 to 3.1 over the experimental period. Overall, these observations are very similar to those reported by Krattenmacher et al. (2019) and Shonka-Martin et al. (2019). At the end of the experimental period, beginning at roughly 125 DIM, disruptions were observed in both DMI and FPCM yield (Figure 2A and B, respectively). These disruptions were possibly caused by the movement of the animals from the main freestall barn to the tiestall portion of the barn for methane testing and influenced estimates of feed efficiency during this period. Correlations and summary statistics of untransformed and smoothed input variables are provided in Supplemental Tables S2 and S3 (https://doi.org/10.3168/jds.2019 -17414), respectively. All smoothed variables were strongly correlated $(r \geq 0.69)$ with their untransformed counterparts; however, a notable decrease in variation can be seen across all measures following the smooth- ing process (Supplemental Table S3; https://doi.org/10 $.3168 /$ jds.2019-17414).

\section{Gross Feed Efficiency}

The GFE displayed asymptotic behavior over the course of the experimental period (Supplemental Figure S1; https://doi.org/10.3168/jds.2019-17414). At the onset of lactation, when increases in FPCM yield outpaced those of DMI, GFE was highest at $2.7 \mathrm{~kg}$ of $\mathrm{FPCM} / \mathrm{kg}$ of DM on average. As DMI increased and FPCM yield stabilized, GFE decreased until stabilizing at approximately $1.6 \mathrm{~kg}$ of $\mathrm{FPCM} / \mathrm{kg}$ of DM. Low correlations were observed between GFE and both BW $(r=0.106)$ and BCS $(r=0.266)$, and moderate correlations were observed with DMI, FPCM, $\triangle \mathrm{BW}$, and $\triangle \mathrm{BCS}$ (Table 2). These correlations suggest that GFE is more closely associated with decreased DMI compared with increased FPCM, although the overall relationship is unsurprising given that GFE is the ratio between the two. The negative relationships of GFE to both $\triangle \mathrm{BW}$ and $\triangle \mathrm{BCS}$ suggest that the mobilization of body reserves plays a role in inflating GFE in early lactation.
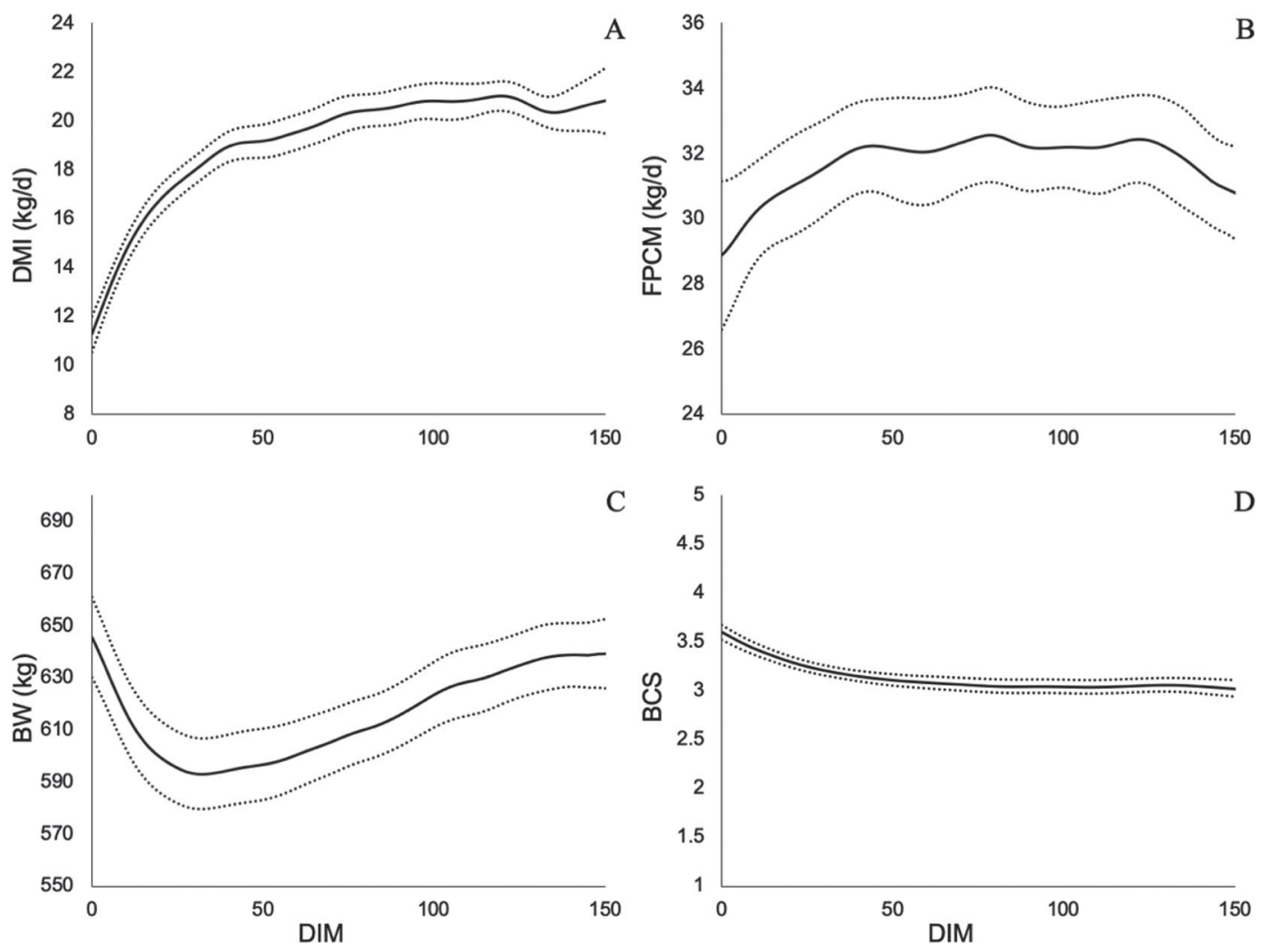

Figure 2. Daily means of DMI (A), FPCM yield (fat- and protein-corrected milk; B), BW (C), and BCS (D). Solid lines indicate daily mean; dotted lines indicate bounds of $95 \%$ CI about the daily means. 


\section{Return Over Feed Costs}

Unlike GFE, average ROFC increased from Can $\$ 15.87$ at the onset of lactation to a peak of Can $\$ 19.02$ by 14 DIM (Supplemental Figure S2; https://doi.org/ 10.3168/jds.2019-17414). This result can be justified by the differential in rates of increase of both DMI and FPCM yield during this time. The ROFC then remained relatively stable until 125 DIM, with minor fluctuations over a range of roughly Can $\$ 0.50$ per day. At the end of the period, ROFC began to decline due to the decline in FPCM yield. The ROFC displayed a low correlation with DMI $(r=0.184$; Table 2$)$ but was much more closely associated with FPCM yield $(r=$ 0.963), which is likely due to the substantially higher dollar values used for milk components compared with feed costs. The ROFC was also the only measure to be positively associated with DMI. Due to the external influences of both commodity and milk component prices on this metric, it is more suitable to view ROFC as the "economic" efficiency of an animal rather than the "biological" efficiency.

\section{Regression-Based Measures}

It was confirmed that both RFI and REI were not correlated with any of the factors in the models (Table 2 ), and visual assessment (data not shown) confirmed no discernable trends in the residuals. The estimated regression coefficients for each model are provided in Supplemental Table S4 (https://doi.org/10.3168/jds .2019-17414). The coefficient of $0.11 \mathrm{Mcal} / \mathrm{d}$ per $\mathrm{kg}^{0.75}$ for $\mathrm{MBW}$ in the REI model was slightly higher than the coefficient of $0.08 \mathrm{Mcal} / \mathrm{d}$ per $\mathrm{kg}^{0.75}$ used by $\mathrm{NRC}$ (2001) to estimate maintenance $\mathrm{NE}_{\mathrm{L}}$ expenditures. The inclusion of the fixed DIM term in both models allowed for the partitioning of temporal effects, allowing for the estimation of average partial efficiencies for each energy sink within animal over the experimental period.

The fixed effect solutions for DIM and residual diagnostic plots for RFI and REI models are presented in Supplemental Figure S3 (https://doi.org/10.3168/jds .2019-17414). The plots of the fixed effect solutions for each DIM for both models (Supplemental Figures S3a and S3d; https://doi.org/10.3168/jds.2019-17414) show that increases in both $\mathrm{DMI}$ and $\mathrm{NE}_{\mathrm{L}}$ intake displayed a logarithmic behavior with the same fluctuations near the end of the experimental period, as seen with GFE and ROFC. Over the experimental period, residuals did not show any discernable bias over time (Supplemental Figures S3b and S3e; https://doi.org/10.3168/jds.2019 -17414) and tended to be within $2.5 \mathrm{~kg}$ of $\mathrm{DM} / \mathrm{d}$ for $\mathrm{RFI}$ and $5 \mathrm{Mcal}$ of $\mathrm{NE}_{\mathrm{L}} / \mathrm{d}$ for REI. However, estimates fluctuated on a daily basis, with predicted intakes for some animals diverging substantially from observed intakes. When comparing observed and predicted intakes (Supplemental Figures S3c and S3f; https://doi.org/ 10.3168/jds.2019-17414), predicted intakes for both models diverged at low intakes, with some extreme instances of overprediction. As the level of intake moved from moderate to high, both models underpredicted intakes. These results suggest that these models have a range over which their predictive abilities remain sound. Outside of this range, estimates of nutrient intakes, and subsequently the predicted feed efficiency, may no longer be valid. This is the crux of using regression models to estimate feed efficiency: are animals divergent because they use feed more efficiently or because the model used has a low predictive ability? To obtain the most accurate estimates of efficiency using these models, animals with a higher degree of homogeneity in both nutrient intakes and energy sinks should be used to maximize the predictive abilities of the models used. In contrast, increased heterogeneity within a cohort ne-

Table 2. Phenotypic correlations of feed efficiency measures to smoothed input variables ${ }^{1}$

\begin{tabular}{|c|c|c|c|c|c|c|c|}
\hline Variable & GFE & ROFC & RFI & REI & $\mathrm{NEE}_{\mathrm{L}}$ & $\mathrm{NEE}_{\mathrm{M}}$ & $\mathrm{NEE}_{\mathrm{F}}$ \\
\hline DMI & -0.654 & 0.184 & 0.635 & 0.620 & -0.102 & -0.479 & -0.557 \\
\hline FPCM & 0.414 & 0.963 & $\begin{array}{c}0 \\
(1.00)\end{array}$ & $\begin{array}{c}0.002 \\
(0.86)\end{array}$ & 0.598 & -0.251 & -0.060 \\
\hline BW & 0.106 & 0.297 & $\begin{array}{r}-0.001 \\
(0.89)\end{array}$ & $\begin{array}{r}-0.002 \\
(0.89)\end{array}$ & 0.062 & 0.119 & 0.126 \\
\hline$\Delta \mathrm{BW}$ & -0.475 & -0.061 & $\begin{array}{c}0 \\
(1.00)\end{array}$ & $\begin{array}{l}0 \\
(1.00)\end{array}$ & 0.324 & 0.268 & -0.504 \\
\hline BCS & 0.266 & -0.104 & $\begin{array}{c}0 \\
(1.00)\end{array}$ & $\begin{array}{l}0 \\
(1.00)\end{array}$ & -0.186 & 0.131 & 0.390 \\
\hline$\triangle \mathrm{BCS}$ & -0.458 & -0.055 & $\begin{array}{l}0 \\
(1.00)\end{array}$ & $\begin{array}{l}0 \\
(1.00)\end{array}$ & 0.251 & 0.226 & -0.580 \\
\hline
\end{tabular}

${ }^{1}$ Correlations were statistically significant at $P<0.001$ unless noted otherwise in brackets. GFE $=$ gross feed efficiency; ROFC = return over feed costs; $\mathrm{RFI}=$ residual feed intake; REI = residual net energy intake; $\mathrm{NEE}_{\mathrm{L}}$ $=\mathrm{NE}_{\mathrm{L}}$ efficiency of lactation; $\mathrm{NEE}_{\mathrm{M}}=\mathrm{NE}_{\mathrm{L}}$ efficiency of maintenance; $\mathrm{NEE}_{\mathrm{F}}=\mathrm{NE}_{\mathrm{L}}$ efficiency of reserve energy flux; FPCM = fat- and protein-corrected milk. 
cessitates the use of more complex models to accurately characterize the various energy sinks. Both scenarios necessitate the use of larger cohorts of animals to obtain sufficient statistical power.

\section{Net Energy Modeling}

A graphical overview of the average net energy dynamics is provided in Figure 3. Average maintenance requirements were consistently from 9.5 to $10 \mathrm{Mcal} / \mathrm{d}$ across the entire experimental period. Both $\mathrm{NE}_{\mathrm{L}}$ intake and NELact mirrored the behaviors of their corresponding driving variables (DMI and FPCM yield, respectively). Body reserves were estimated to contribute approximately $10 \mathrm{Mcal}$ of $\mathrm{NE}_{\mathrm{L}} / \mathrm{d}$ at the onset of lactation, on average. These contributions steadily decreased until 55 DIM, after which energy began to be contributed back to body reserves at a rate of roughly $1 \mathrm{Mcal} / \mathrm{d}$, with minor fluctuations for the remainder of the period. The average net energy balance consistently increased from $-10 \mathrm{Mcal} / \mathrm{d}$ at the onset of lactation to approximately $-1 \mathrm{Mcal} / \mathrm{d}$ by $75 \mathrm{DIM}$.

The average calculated net energy efficiencies $\left(\mathrm{NEE}_{\mathrm{L}}\right.$, $\mathrm{NEE}_{\mathrm{M}}$, and $\mathrm{NEE}_{\mathrm{F}}$ ) are presented in Figure 4. We found that $\mathrm{NEE}_{\mathrm{L}}$ rose slowly from approximately 66 to $77 \%$ by 40 DIM, after which it slowly declined to $70 \%$ by 150 DIM, with minor fluctuations. The observed $\mathrm{NEE}_{\mathrm{L}}$ is in agreement with theoretical values reported by Baldwin et al. (1980). By contrast, $\mathrm{NEE}_{\mathrm{M}}$ remained relatively stable at $31 \%$ over the course of the experimental period, whereas $\mathrm{NEE}_{\mathrm{F}}$ decreased from 36 to $6 \%$ over the first 45 DIM, after which it remained relatively

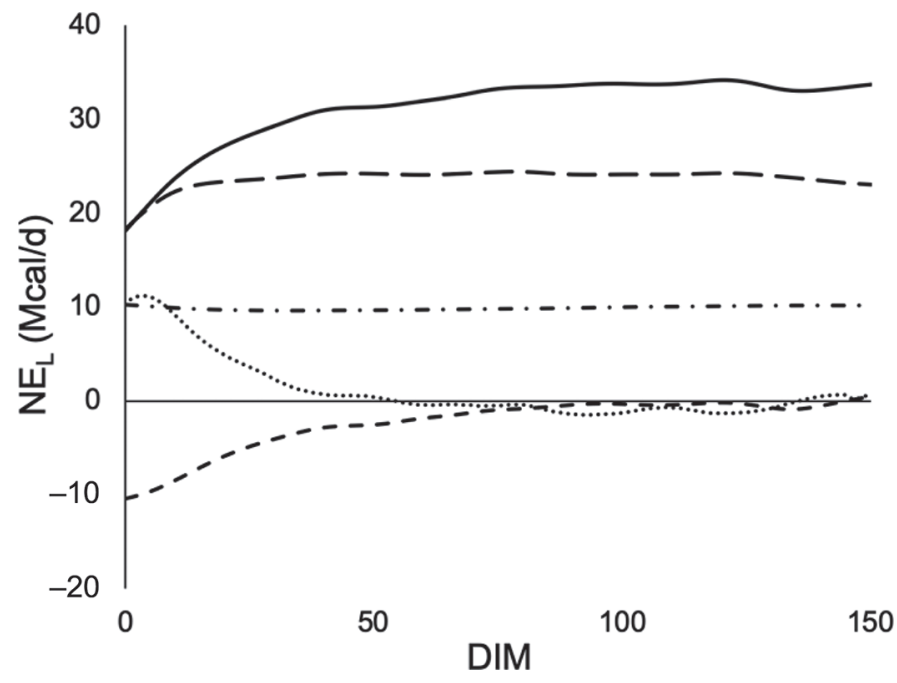

Figure 3. Daily mean net energy fluxes. Values are $\mathrm{NE}_{\mathrm{L}}$ intake (solid line), milk $\mathrm{NE}_{\mathrm{L}}$ output (long dash), maintenance expenditures (dash-dot), reserve energy flux (dotted line), and net energy balance (short dash).

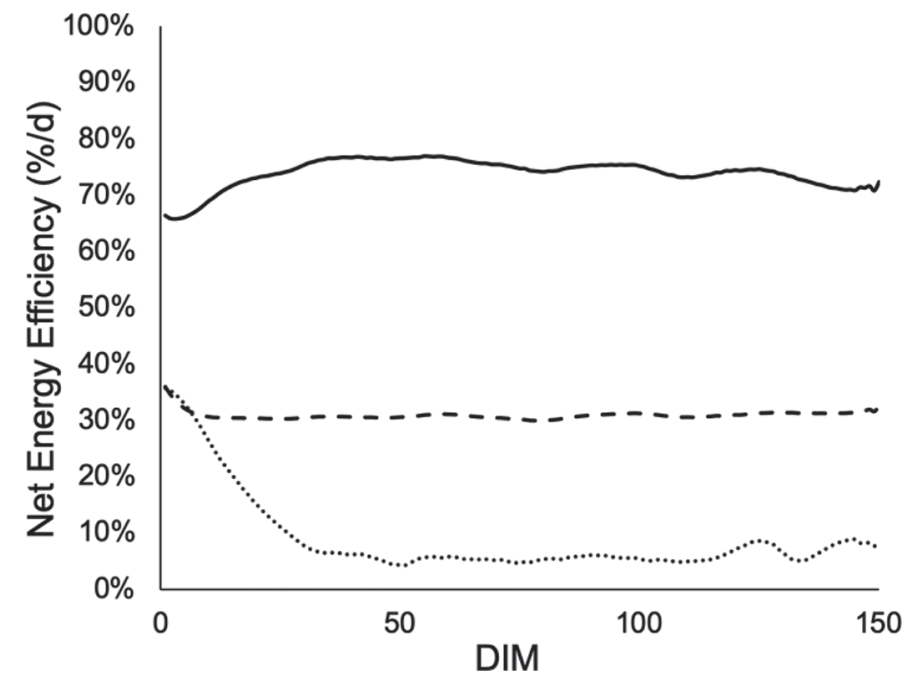

Figure 4. Daily mean $\mathrm{NE}_{\mathrm{L}}$ efficiency. Values are net energy efficiencies of lactation (solid line), maintenance (short dash), and body reserve flux (dotted line).

constant. Notably, at times the values of $\mathrm{NEE}_{\mathrm{L}}$ and $\mathrm{NEE}_{\mathrm{M}}$ do not sum to unity; this represents the accumulation of error derived from inaccuracies in measurements, the smoothing process, and the model equations themselves.

Analysis revealed that $\mathrm{NEE}_{\mathrm{L}}$ displayed weak correlations with input variables except FPCM $(r=0.598$; Table 2), suggesting that lactation efficiency tended to increase concurrently with FPCM yield and was independent of body size or DMI. Of all input variables, $\mathrm{NEE}_{\mathrm{M}}$ was most associated with DMI $(r=-0.479)$. This negative association represents the dilution of maintenance requirements by the increase in NEAvail following increased DMI and $\mathrm{NE}_{\mathrm{L}}$ intake. Moderate correlations were observed between $\mathrm{NEE}_{\mathrm{F}}$ and the variables driving energy flux to and from body reserves (DMI, $\triangle \mathrm{BW}$, and $\triangle \mathrm{BCS}$; Table 2), which is to be expected.

\section{Behavior of Standardized Measures}

Because the measures of feed efficiency described herein were scaled differently, converting daily estimates to standardized scores based on the distribution of estimates on that day within the cohort allows for direct comparison of the behavior of each feed efficiency measure over time while minimizing temporal effects. A representative example of the raw and standardized estimates from 1 animal are presented in Figures 5 and 6, respectively. To aid in the comparisons of the behavior of each measure, the signs of RFI and REI estimates were reversed in the standardization process so that each measure of feed efficiency would be positive when efficiency is high and negative when efficiency is low. 

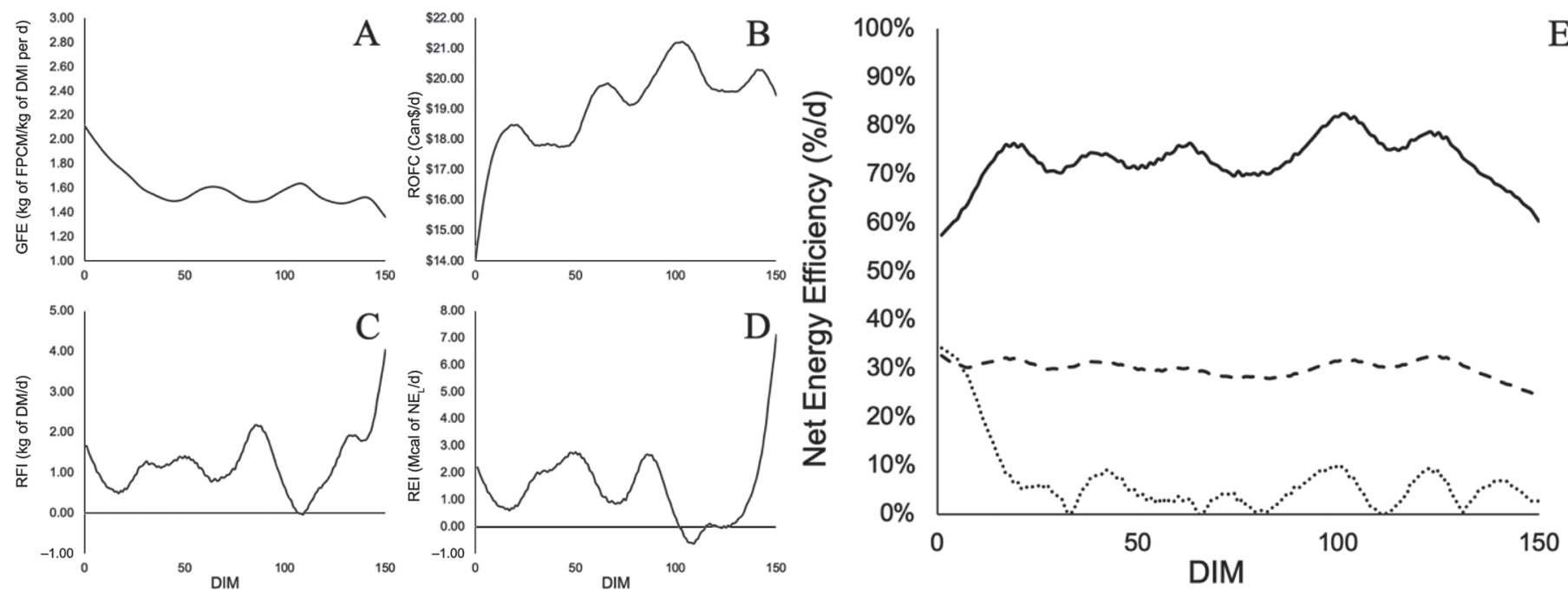

Figure 5. Representative plots of raw daily feed efficiency metrics. (A) Gross feed efficiency (GFE); (B) return over feed costs (ROFC); (C) residual feed intake (RFI); (D) residual $\mathrm{NE}_{\mathrm{L}}$ intake (REI); (E) $\mathrm{NE}_{\mathrm{L}}$ efficiencies of lactation (solid line), maintenance (short dash), and reserve energy flux (dotted line). FPCM $=$ fat- and protein-corrected milk. Can $\$ 1.00$ equals approximately US $\$ 0.77$.

The standardized measures displayed the same temporal pattern as the raw measures. In general, the pattern of each measure followed similar trends in terms of increases or decreases, although at times these changes were of different magnitudes across measures. The exception appeared to be $\mathrm{NEE}_{\mathrm{F}}$, which at times moved in the opposite direction from the other efficiency measures, reflective of its bidirectionality. As measures approached the mean of 0 , daily estimates for all values tended to be similar, whereas estimates tended to be more dispersed when efficiency values became more extreme. Correlations between measures of feed efficiency, either raw or standardized, are presented in Table 3. The majority of correlations remained unaffected by standardization, with some notable exceptions: GFE exhibited significant increases in correlations with ROFC, RFI, REI, and $\mathrm{NEE}_{\mathrm{L}}$ and reduced correlations with $\mathrm{NEE}_{\mathrm{M}}$ and $\mathrm{NEE}_{\mathrm{F}}$. These changes highlight that this measure is strictly associated with productive energy expenditure. Correlations between $\mathrm{NEE}_{\mathrm{F}}$ and ROFC, RFI, REI, $\mathrm{NEE}_{\mathrm{L}}$, and $\mathrm{NEE}_{\mathrm{M}}$ increased but were still weak. Additionally, both RFI and REI were more strongly correlated with $\mathrm{NEE}_{\mathrm{M}}$ compared with either $\mathrm{NEE}_{\mathrm{L}}$ or $\mathrm{NEE}_{\mathrm{F}}$ (Table 3), suggesting that maintenance

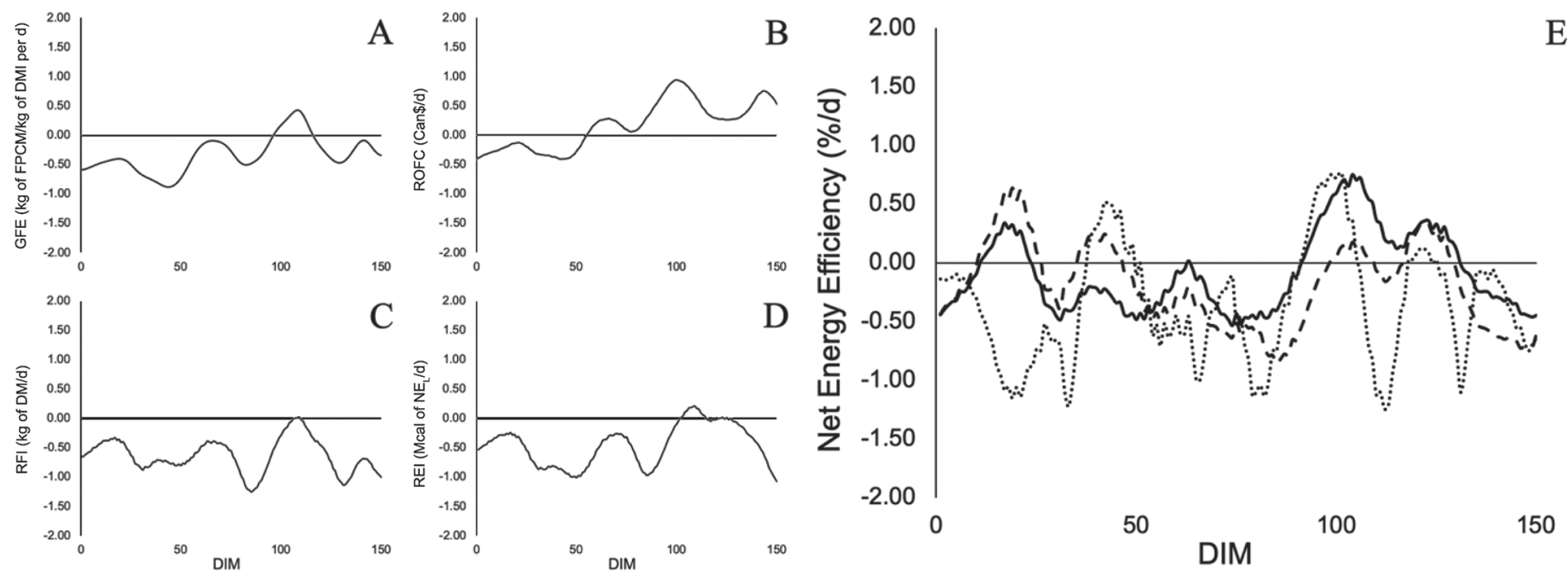

Figure 6. Representative plots of standardized daily feed efficiency metrics. (A) Gross feed efficiency (GFE; FPCM = fat- and protein-corrected milk); (B) return over feed costs $(\mathrm{ROFC})$; (C) residual feed intake (RFI); (D) residual $\mathrm{NE}_{\mathrm{L}}$ intake (REI); (E) NE $\mathrm{L}$ efficiencies of lactation (solid line), maintenance (short dash), and reserve energy flux (dotted line). Can $\$ 1.00$ equals approximately US $\$ 0.77$. 
Table 3. Correlations between daily measures of feed efficiency and $\mathrm{NE}_{\mathrm{L}}$ balance ${ }^{1}$

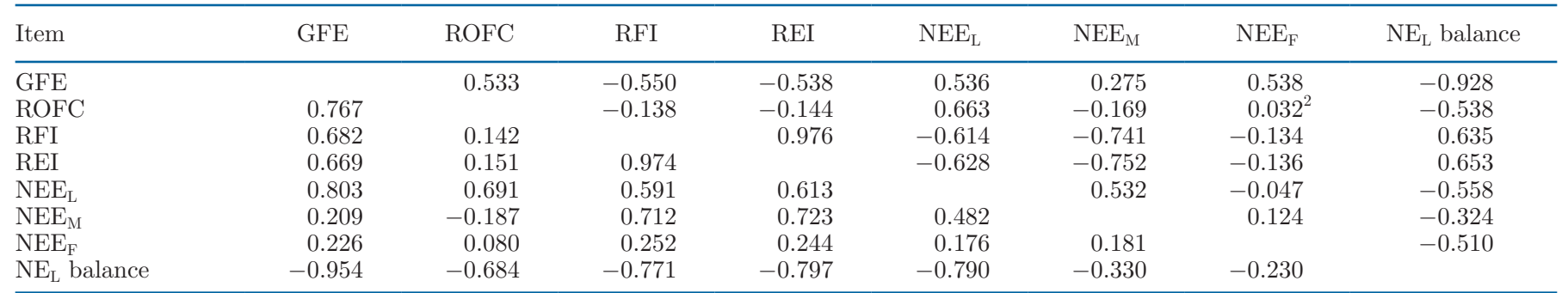

${ }^{1}$ All correlations were statistically significant at $P<0.001$ unless indicated. Values above the diagonal are correlations between raw estimates, values below the diagonal are correlations between standardized values. GFE $=$ gross feed efficiency; ROFC $=$ return over feed costs; RFI $=$ residual feed intake; $\mathrm{REI}=$ residual net energy intake; $\mathrm{NEE}_{\mathrm{L}}=\mathrm{NE}_{\mathrm{L}}$ efficiency of lactation; $\mathrm{NEE}_{\mathrm{M}}=\mathrm{NE}_{\mathrm{L}}$ efficiency of maintenance; $\mathrm{NEE} F$ $\mathrm{NE}_{\mathrm{L}}$ efficiency of reserve energy flux.

${ }^{2} P=0.012$.

energy expenditures may contribute more to variation in these measures than do those related to production. Overall, the similarities between both standardized behavior and raw (compared with standardized) correlations suggest that a given animal can be classified as more or less efficient than another, regardless of the measure used (excluding $\mathrm{NEE}_{\mathrm{F}}$ ).

\section{Efficiency and Energy Balance}

Correlations between daily $\mathrm{NE}_{\mathrm{L}}$ balance and each measure of feed efficiency are provided in Table 3. We found that GFE exhibited a very strong negative relationship with energy balance $(r=-0.928)$, further implicating mobilization of body reserves in the inflation of this measure. Similarly, $\mathrm{NEE}_{\mathrm{F}}$ was moderately correlated $(r=-0.510)$ with energy balance; this reflects the bidirectional behavior of this flux, which accounts for both energy being mobilized from the body, as during a period of negative energy balance (NEB), as well as energy being sequestered into body reserves, the latter of which occurred at a much lower rate. When comparing the correlation between the standardized values of $\mathrm{NEE}_{\mathrm{F}}$ and $\mathrm{NE}_{\mathrm{L}}$ balance, the relationship became much weaker $(r=-0.230)$.

Both RFI and REI were strongly associated with energy balance ( $r=0.635$ and 0.653 , respectively). Similarly, $\mathrm{NEE}_{\mathrm{L}}(r=-0.558)$ and ROFC $(r=-0.538)$ were moderately correlated with energy balance. The associations between these measures and NEB became stronger when examining the standardized values (Table 3). These results suggest that on a given day, animals who are classified as more feed efficient using these measures are more likely to have a lower energy balance.

Prolonged NEB has been associated with a variety of detrimental health implications (Collard et al., 2000). Although the given measures of efficiency may be associated with NEB on a daily basis, future work examining the relationships of feed efficiency with both the magnitude and duration of NEB and associated health and production outcomes would help address these concerns. Furthermore, maintaining a state of positive energy balance is also undesirable, as it represents inefficient energy use and could result in the animal gaining excess condition, which can lead to other detrimental outcomes (Roche, 2006). As such, energy balance should be close to 0 when an adequate degree of condition is reached, to maximize efficiency without compromising animal health.

\section{Variance of Feed Efficiency Measures}

Descriptive statistics of each feed efficiency measure are presented in Table 4. In the context of using these measures to estimate breeding values for genetic selection, an ideal measure would have low within-animal variation, allowing for a reduced number of records to estimate the "true" efficiency of the animal (higher accuracy and reliability), and high variation across animals to allow for increased response to selection (Falconer and Mackay, 1996). Low within-animal variation is also advantageous from a management standpoint due to the reduced cost of estimating the feed efficiency of an animal. Similar to within-animal variation, repeatability is a measure of the accuracy and consistency of a phenotype measured repeatedly on an animal (Nakagawa and Schielzeth, 2010) and also serves as an estimate of the upper limit of the heritability of that trait (Falconer and Mackay, 1996), which will affect the potential for genetic improvement. As previously discussed, the smoothing process performed on the raw data significantly reduced the variation and inflated the associated repeatability estimates of each measure (Supplemental Table S3; https://doi.org/10.3168/jds .2019-17414), particularly for measures that originally had a high degree of variation $\left(\mathrm{DMI}, \mathrm{NE}_{\mathrm{L}}\right.$ intake, and FPCM yield). Because all indices of feed efficiency used 
Table 4. Summary statistics of feed efficiency (FE) measures

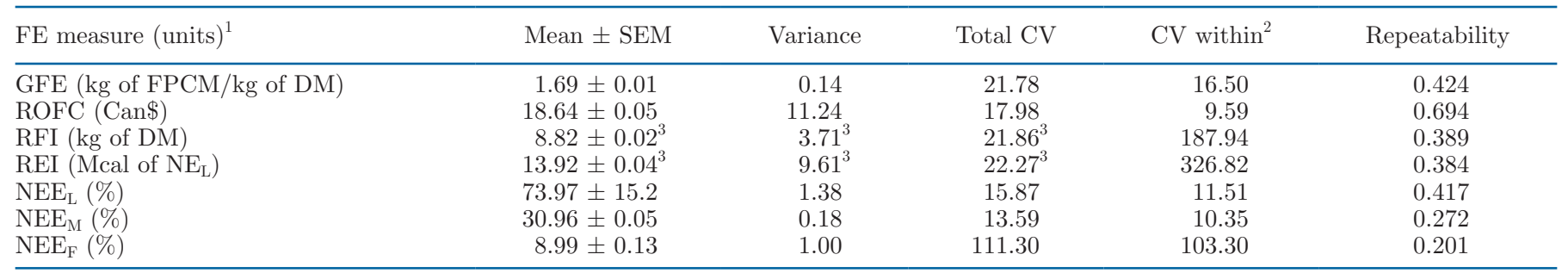

${ }^{1} \mathrm{GFE}=$ gross feed efficiency; FPCM $=$ fat- and protein-corrected milk; ROFC = return over feed costs; RFI = residual feed intake; REI $=$ residual net energy intake; $\mathrm{NEE}_{\mathrm{L}}=\mathrm{NE}_{\mathrm{L}}$ efficiency of lactation; $\mathrm{NEE}_{\mathrm{M}}=\mathrm{NE}_{\mathrm{L}}$ efficiency of maintenance; $\mathrm{NEE}_{\mathrm{F}}=\mathrm{NE}_{\mathrm{L}}$ efficiency of reserve energy flux. Can\$1.00 equals approximately US\$0.77.

${ }^{2}$ Average within-animal CV.

${ }^{3}$ Based on measures re-centered around the intercept of each model.

the same smoothed records, the amount by which the variation is dampened should be comparable across measures. However, the "true" repeatability of each measure is lower than that calculated presently (Table 4) due to this decrease in variation in the input records, although measures based on $\mathrm{BW}$ and $\mathrm{BCS}\left(\mathrm{NEE}_{\mathrm{M}}\right.$ and $\mathrm{NEE}_{\mathrm{F}}$ ) would be less affected due to the high repeatability of the untransformed records.

Within animals, measures of ROFC, $\mathrm{NEE}_{\mathrm{M}}$, and $\mathrm{NEE}_{\mathrm{L}}$ had moderate daily variation $(\mathrm{CV}<15 \%)$, whereas $\mathrm{NEE}_{\mathrm{F}}, \mathrm{RFI}$, and REI had extreme $(\mathrm{CV}>$ $100 \%$ variation across the experimental period. We found that ROFC had the highest repeatability of all feed efficiency measures $(R=0.694)$; however, this could be due in part to the static values used for feed and milk component prices. In a more realistic situation of fluctuating prices, it is probable that the repeatability of ROFC would be lower than presented here, due to increased variation. The dynamic behavior of body reserve mobilization potentially inflated the $\mathrm{CV}$ of $\mathrm{NEE}_{\mathrm{F}}$; the high degree of mobilization at the onset of lactation would increase the variance of measures within animal, whereas the much lower rates of mobilization or sequestration of energy (or both) for the remainder of the period would drive the mean lower. This also affects the repeatability of $\mathrm{NEE}_{\mathrm{F}}(r=0.201)$. In contrast to the other measures, RFI and REI depend on both the individual animal and the cohort used to parameterize each model; thus, it follows that the observed withinanimal variation of these measures is not due only to the individual animal but also to variation within the cohort. However, these regression-based measures, in addition to $\mathrm{NEE}_{\mathrm{L}}(r=0.417)$, showed the highest observed repeatability values following ROFC, which were similar to previously reported heritability estimates for RFI (Veerkamp et al., 1995; Basarab et al., 2003; Bottje and Carstens, 2009). The repeatability of $\mathrm{NEE}_{\mathrm{M}}$ was lower $(r=0.272)$ than most other measures. Because body size is generally considered to be highly heritable, it may prove easier to genetically select for lower maintenance energy expenditures through reduced body size as opposed to selecting for the efficiency with which energy is used for maintenance.

Variation across animals was much more similar between measures, ranging between 13 and $23 \%$ of the mean, except $\mathrm{NEE}_{\mathrm{F}}$, which was substantially higher $(\mathrm{CV}=111.3 \%)$. This feature of $\mathrm{NEE}_{\mathrm{F}}$ suggests an opportunity to improve overall animal efficiency by targeting a reduction in reserve energy flux with management and breeding decisions. Considering Eq. 2-24 and 2-25 of the net energy model (NRC, 2001; Supplemental Table S1; https://doi.org/10.3168/jds .2019-17414), approximately $30 \%$ of energy is lost by cycling through body reserves, representing a major inefficiency. Furthermore, the mobilization of adipose tissue acts to reduce voluntary feed intake through the hepatic oxidation theory (as reviewed by Allen et al., 2009), which can exacerbate NEB, particularly in early lactation. Drackley (2016) proposed targeting a BCS of 2.0 to 3.0 (out of 5 ) at calving to reduce the mobilization of adipose tissue and promote voluntary feed intake in the periparturient period. This would serve to avoid excessive total energy flux through body reserves, making overall energy partitioning more efficient. From a breeding perspective, it would likewise be advantageous to select for animals that are able to minimize gross fluctuations in BCS over the course of multiple lactations, similar to the reduction in maintenance requirements through breeding for smaller body size, as previously discussed by Dickerson (1978) and VandeHaar et al. (2016). Wall et al. (2008) derived economic values for traits related to body reserve mobilization, which would help integrate this trait into profitabilitybased genetic selection indices, such as the Pro\$ index developed by Lactanet (Guelph, ON, Canada).

The lower degree of variation in both $\mathrm{NEE}_{\mathrm{M}}(\mathrm{CV}=$ $13.59 \%)$ and $\mathrm{NEE}_{\mathrm{L}}(\mathrm{CV}=15.87 \%)$ across animals may be indicative of the tight thermodynamic constraints 
on the biochemical processes underpinning these traits, which could make selection for improvement of these traits more challenging. Similarly to ROFC, the lower degree of variation $(\mathrm{CV}=17.98 \%)$ negatively affects potential for genetic progress; given that this measure was highly correlated with FPCM yield $(r=0.963$; Table 2), it is likely to be more influenced by changes in price, making it more suited for use in management decisions. Both RFI $(\mathrm{CV}=21.86 \%)$ and REI (CV = $22.27 \%$ ) had the highest degree of variation following $\mathrm{NEE}_{\mathrm{F}}$; however, this is heavily influenced by the models used to generate these measures. Depending on the factors included in the intake prediction models, more or less of the observed variation will be partitioned into these measures; with a poorly specified model, more variation can be partitioned into the residual, whereas including terms that adequately capture the variation in intakes will reduce the residual error variance. Model-fitting errors of this nature have been shown to contribute up to $47 \%$ of the variance in similar regression models (Fischer et al., 2018b). The degree of variation in GFE was similar to that of RFI and REI (CV = $21.78 \%$ ), with a moderate repeatability similar to that of $\mathrm{NEE}_{\mathrm{L}}(R=0.424)$. Due to the strong association of this measure with NEB and reduced DMI, however, using GFE for either management or breeding decisions could lead to detrimental health and production outcomes, as previously discussed.

\section{Static vs. Dynamic Maintenance Requirements}

The regression coefficient for MBW estimated by the REI model was higher than the $0.08 \mathrm{Mcal} / \mathrm{d}$ per $\mathrm{kg}^{0.75}$ used to estimate NEMaint in the NRC (2001) model. The coefficient used in the NRC model was originally derived from data on fasting, nonpregnant dry cows housed in metabolic chambers, using both indirect calorimetry and regression, with an additional allowance for activity (NRC, 2001). This coefficient underestimates maintenance expenditures due to the additional costs imposed during lactation. As lactation becomes established, increases in milk yields will drive an increase in voluntary DMI. To facilitate the increased absorption of additional nutrients, the gastrointestinal tract will grow until the tissues consume approximately 15 to $25 \%$ of incoming energy (Cant et al., 1996). The high metabolic activity of these tissues, attributed predominantly to protein turnover and ion transport, could result in substantial increases in maintenance energy expenditure (Baldwin et al., 1980; McBride and Kelly, 1990). Estimation of maintenance energy losses using indirect calorimetry (Flatt et al., 1969; Yan et al., 1997), regression of retained energy on ME intake (Agnew et al., 2003; Kebreab et al., 2003), or matching predicted and observed BW gain (Ellis et al., 2006) suggests that lactation imposes an additional 10 to $30 \%$ in maintenance energy costs. As such, it is possible that the partial efficiency of maintenance estimated by the REI equation $(b=0.11)$ may be more representative of the average maintenance energy requirements of these animals over the experimental period.

\section{Time Frame of Feed Efficiency}

A critical aspect of estimating feed efficiency of any animal is the period of time for which efficiency is measured. In the current study, we observed that regardless of the measure used, feed efficiency is dynamic and changes on a daily basis. This is reflective of the underlying biology of the animal; although average intakes may be relatively stable over time, daily fluctuations in feed intake are normal as the animal makes short-term corrections to ensure that nutrient demands are met (as reviewed by Allen, 2000; Forbes, 2000, 2007). Furthermore, the nonlinear nature of the lactation curve (particularly in multiparous animals) contributes further to daily variations in efficiency. Additionally, the frequency of measurements of BCS and BW influence the characterization of changes in body reserves (Fischer et al., 2018b). From a practical standpoint, knowledge of feed efficiency on a daily basis is of little importance; however, the results of this study showed that regardless of the measure used, the "true" efficiency of an animal is unlikely to be estimated from a small number of measurements due to day-to-day variability. Connor et al. (2012) demonstrated the possibility of estimating full-lactation RFI using data from a 100-d period in late lactation, and more recently using a smaller 70 -d period between 150 and 220 DIM (Connor et al., 2019). Using a measure of efficiency with a lower degree of within-animal variation and higher repeatability, such as $\mathrm{NEE}_{\mathrm{L}}$, could potentially reduce this test period even further.

\section{CONCLUSIONS}

Regardless of the measure of feed efficiency used, estimates change on a daily basis. Furthermore, changes in daily estimates of feed efficiency generally follow a similar pattern across measures, although the magnitude of the observed change may differ. With sufficient data, modeling net energy efficiency can estimate feed efficiency comparable to that of regression-based measures, independent of the cohort and with more biological relevance. Measures such as ROFC may be more suited for management decisions, whereas others, particularly that pertaining to reserve energy flux, may be more applicable for use in breeding programs. Further 
work investigating the associations of feed efficiency with the duration and intensity of negative energy balance is warranted, as is determining an optimal sampling period of the lactation to accurately characterize production cycle efficiency with minimal observations.

\section{ACKNOWLEDGMENTS}

The authors thank the staff at the Livestock Research and Innovation Centre-Dairy (Centre Wellington, ON, Canada) for their continued efforts with data collection. We gratefully acknowledge funding by the Efficient Dairy Genome Project, funded by Genome Canada (Ottawa), Genome Alberta (Calgary, Canada), Ontario Genomics (Toronto, Canada), Alberta Ministry of Agriculture (Edmonton, Canada), Ontario Ministry of Research and Innovation (Toronto, Canada), Ontario Ministry of Agriculture, Food and Rural Affairs (Guelph, Canada), Canadian Dairy Network (Guelph), GrowSafe Systems (Airdrie, Canada), Alberta Milk (Edmonton, Canada), Victoria Agriculture (Melbourne, Australia), Scotland's Rural College (Edinburgh, UK), USDA Agricultural Research Service (Washington, DC), Qualitas AG (Zug, Switzerland), and Aarhus University (Denmark). The authors have not stated any conflicts of interest.

\section{REFERENCES}

Agnew, R. E., T. Yan, J. J. Murphy, C. P. Ferris, and F. J. Gordon. 2003. Development of maintenance energy requirement and energetic efficiency for lactation from production data of dairy cows. Livest. Prod. Sci. 82:151-162. https://doi.org/10.1016/S0301 $-6226(03) 00014-9$.

Allen, M. S. 2000. Effects of diet on short-term regulation of feed intake by lactating dairy cattle. J. Dairy Sci. 83:1598-1624. https:// doi.org/10.3168/jds.S0022-0302(00)75030-2.

Allen, M. S., B. J. Bradford, and M. Oba. 2009. Board invited review: The hepatic oxidation theory of the control of feed intake and its application to ruminants. J. Anim. Sci. 87:3317-3334. https://doi .org/10.2527/jas.2009-1779.

Baldwin, R. L., N. E. Smith, J. Taylor, and M. Sharp. 1980. Manipulating metabolic parameters to improve growth rate and milk secretion. J. Anim. Sci. 51:1416-1428. https://doi.org/10.2527/ jas1981.5161416x.

Basarab, J. A., M. A. Price, J. L. Aalhus, E. K. Okine, W. M. Snelling, and K. L. Lyle. 2003. Residual feed intake and body composition in young growing cattle. Can. J. Anim. Sci. 83:189-204. https:// doi.org/10.4141/A02-065.

Bottje, W. G., and G. E. Carstens. 2009. Association of mitochondrial function and feed efficiency in poultry and livestock species. J. Anim. Sci. 87(Suppl. 14):E48-E63. https://doi.org/10.2527/jas .2008-1379.

Brito, L. F., H. R. Oliveira, T. C. S. Chud, D. J. Seymour, F. Miglior, and F. S. Schenkel. 2019. Breeding dairy cattle for improved feed efficiency: An overview. Pages 101-114 in Proc. 28th Tri-State Dairy Nutrition Conference, Fort Wayne, IN.

Byskov, M. V., A. Fogh, and P. Lovendahl. 2017. Genetic parameters of rumination time and feed efficiency traits in primiparous Holstein cows under research and commercial conditions. J. Dairy Sci. 100:9635-9642. https://doi.org/10.3168/jds.2016-12511.
Cant, J. P., B. W. McBride, and W. J. Croom Jr.. 1996. The regulation of intestinal metabolism and its impact on whole animal energetics. J. Anim. Sci. 74:2541-2553. https://doi.org/10.2527/ 1996.74102541x.

Collard, B. L., P. J. Boettcher, J. C. M. Dekkers, D. Petitclerc, and L. R. Schaeffer. 2000. Relationships between energy balance and health traits of dairy cattle in early lactation. J. Dairy Sci. 83:2683-2690. https://doi.org/10.3168/jds.S0022-0302(00)75162 $-9$.

Connor, E. E., J. L. Hutchison, K. M. Olson, and H. D. Norman. 2012. Triennial Lactation Symposium: Opportunities for improving milk production efficiency in dairy cattle. J. Anim. Sci. 90:1687-1694. https://doi.org/10.2527/jas.2011-4528.

Connor, E. E., J. L. Hutchison, C. P. Van Tassell, and J. B. Cole. 2019. Defining the optimal period length and stage of growth or lactation to estimate residual feed intake in dairy cows. J. Dairy Sci. 102:6131-6143. https://doi.org/10.3168/jds.2018-15407.

Dickerson, G. E. 1978. Animal size and efficiency: Basic concepts. Anim. Prod. 27:367-379.

Drackley, J. K. 2016. The importance of BCS management to cow welfare, performance and fertility. Pages 195-206 in Proc. Western Canadian Dairy Seminar, Red Deer, AB.

Ellis, J. L., F. Qiao, and J. P. Cant. 2006. Evaluation of net energy expenditures of dairy cows according to body weight changes over a full lactation. J. Dairy Sci. 89:1546-1557. https://doi.org/10.3168/ jds.S0022-0302(06)72222-6.

Falconer, D. S., and T. F. C. Mackay. 1996. Introduction to Quantitative Genetics. 4th ed. Longman, Essex, UK.

Fischer, A., R. Delagarde, and P. Faverdin. 2018a. Identification of biological traits associated with differences in residual energy intake among lactating Holstein cows. J. Dairy Sci. 101:4193-4211. https://doi.org/10.3168/jds.2017-12636.

Fischer, A., N. C. Friggens, D. P. Berry, and P. Faverdin. 2018b. Isolating the cow-specific part of residual energy intake in lactating dairy cows using random regressions. Animal 12:1396-1404.

Flatt, W. P., P. W. Moe, and L. A. Moore. 1969. Influence of pregnancy and ration composition on energy utilization by dairy cows. Page 123 in Energy Metabolism of Farm Animals No. 4. Eur. Assoc. Anim. Prod. Publ. No. 12, Warsaw, Poland.

Flay, H. E., B. Kuhn-Sherlock, K. A. Macdonald, M. Camara, N. Lopez-Villalobos, D. J. Donaghy, and J. R. Roche. 2019. Hot topic: Selecting cattle for low residual feed intake did not affect daily methane production but increased methane yield. J. Dairy Sci. 102:2708-2713. https://doi.org/10.3168/jds.2018-15234.

Forbes, J. M. 2000. Physiological and metabolic aspects of feed intake control. Pages 319-333 in Farm Animal Metabolism and Nutrition. J. P. F. D'Mello, ed. CABI, Egham, UK.

Forbes, J. M. 2007. A personal view of how ruminant animals control their intake and choice of food: Minimal total discomfort. Nutr. Res. Rev. 20:132-146. https://doi.org/10.1017/S0954422407797834.

Kebreab, E., J. France, R. E. Agnew, T. Yan, M. S. Dhanoa, J. Dijkstra, D. E. Beever, and C. K. Reynolds. 2003. Alternatives to linear analysis of energy balance data from lactating dairy cows. J. Dairy Sci. 86:2904-2913. https://doi.org/10.3168/jds.S0022 $-0302(03) 73887-9$.

Koch, R. M., L. A. Swiger, D. Chambers, and K. E. Gregory. 1963. Efficiency of feed use in beef cattle. J. Anim. Sci. 22:486-494. https: //doi.org/10.2527/jas1963.222486x.

Krattenmacher, N., G. Thaller, and J. Tetens. 2019. Analysis of the genetic architecture of energy balance and its major determinants dry matter intake and energy-corrected milk yield in primiparous Holstein cows. J. Dairy Sci. 102:3241-3253. https://doi.org/10 .3168/jds.2018-15480.

McBride, B. W., and J. M. Kelly. 1990. Energy cost of absorption and metabolism in the ruminant gastrointestinal tract and liver: A review. J. Anim. Sci. 68:2997-3010. https://doi.org/10.2527/1990 $.6892997 x$.

Miglior, F., A. Fleming, F. Malchiodi, L. F. Brito, P. Martin, and C. F. Baes. 2017. A 100-year review: Identification and genetic selection of economically important traits in dairy cattle. J. Dairy Sci. 100:10251-10271. https://doi.org/10.3168/jds.2017-12968. 
Mullins, I. L., C. M. Truman, M. R. Campler, J. M. Bewley, and J. H. C. Costa. 2019. Validation of a commercial automated body condition scoring system on a commercial dairy farm. Animals (Basel) 9:E287. https://doi.org/10.3390/ani9060287.

Nakagawa, S., and H. Schielzeth. 2010. Repeatability for Gaussian and non-Gaussian data: A practical guide for biologists. Biol. Rev. Camb. Philos. Soc. 85:935-956. https://doi.org/10.1111/j.1469 $-185 X .2010 .00141 . x$.

NRC (National Research Council). 2001. Nutrient Requirements of Dairy Cattle. 7th rev. ed. Natl. Acad. Sci., Washington, D.C.

Roche, J. F. 2006. The effect of nutritional management of the dairy cow on reproductive efficiency. Anim. Reprod. Sci. 96:282-296. https://doi.org/10.1016/j.anireprosci.2006.08.007.

Seymour, D. J., A. Cánovas, C. F. Baes, T. C. S. Chud, V. R. Osborne, J. P. Cant, L. F. Brito, B. Gredler-Grandl, R. Finocchiaro, R. F. Veerkamp, Y. de Haas, and F. Miglior. 2019. Invited review: Determination of large-scale individual dry matter intake phenotypes in dairy cattle: A systematic review. J. Dairy Sci. 102:7655-7663. https://doi.org/10.3168/jds.2019-16454.

Shonka-Martin. B. N., B. J. Heins, and L. B. Hansen. 2019. Threebreed rotational crossbreds of Montbéliarde, Viking Red, and Holstein compared with Holstein cows for feed efficiency, income over feed cost, and residual feed intake. J. Dairy Sci. 102:3661-3673. https://doi.org/10.3168/jds.2018-15682.

Spurlock, D. M., J. C. M. Dekkers, R. Fernando, D. A. Koltes, and A. Wolc. 2012. Genetic parameters for energy balance, feed efficiency, and related traits in Holstein cattle. J. Dairy Sci. 95:5393-5402. https://doi.org/10.3168/jds.2012-5407.

Thorup, V. M., M. G. G. Chagunda, A. Fischer, M. R. Weisbjerg, and N. C. Friggens. 2018. Robustness and sensitivity of a blueprint for on-farm estimation of dairy cow energy balance. J. Dairy Sci. 101:6002-6018. https://doi.org/10.3168/jds.2017-14290.

Tyrrell, H. F., and J. T. Reid. 1965. Prediction of the energy value of cow's milk. J. Dairy Sci. 48:1215-1223. https://doi.org/10.3168/ jds.S0022-0302(65)88430-2.
USDA-ERS. 2019. Milk cost of production by state. Accessed May 5, 2019. https://www.ers.usda.gov/data-products/milk-cost-of -production-estimates/

VandeHaar, M. J., L. E. Armentano, K. Weigel, D. M. Spurlock, R J. Tempelman, and R. Veerkamp. 2016. Harnessing the genetics of the modern dairy cow to continue improvements in feed efficiency. J. Dairy Sci. 99:4941-4954. https://doi.org/10.3168/jds .2015-10352.

Veerkamp, R. F., G. C. Emmans, A. R. Cromie, and G. Simm. 1995. Variance components for residual feed intake in dairy cows. Livest. Prod. Sci. 41:111-120. https://doi.org/10.1016/0301 -6226(94)00056-D.

Wall, E., M. P. Coffey, and P. R. Amer. 2008. A theoretical framework for deriving direct economic values for body tissue mobilization traits in dairy cattle. J. Dairy Sci. 91:343-353. https://doi.org/10 $.3168 /$ jds.2007-0421.

Yan, T., F. J. Gordon, C. P. Ferris, R. E. Agnew, M. G. Porter, and D. C. Patterson. 1997. The fasting heat production and effect of lactation on energy utilization by dairy cows offered forage-based diets. Livest. Prod. Sci. 52:177-186. https://doi.org/10.1016/S0301 $-6226(97) 00121-8$.

\section{ORCIDS}

D. J. Seymour @ https://orcid.org/0000-0001-6208-8720

A. Cánovas @ https://orcid.org/0000-0002-0036-0757

T. C. S. Chud (1) https://orcid.org/0000-0001-7559-1165

J. P. Cant ๑ https://orcid.org/0000-0003-2021-1764

V. R. Osborne (ㄱ https://orcid.org/0000-0002-8959-8760

C. F. Baes (ㄴ) https://orcid.org/0000-0001-6614-8890

F. S. Schenkel (1) https://orcid.org/0000-0001-8700-0633

F. Miglior (๑ https://orcid.org/0000-0003-2345-8842 